\begin{tabular}{cc}
\hline & International Journal of Engineering \& Technology, $7(4.26)(2018) 226-229$ \\
International Journal of Engineering \& Technology & Website: www.sciencepubco.com/index.php/IJET \\
RPC & Research paper \\
\hline
\end{tabular}

\title{
Innovation of New System of Water Supply for Wudhu
}

\author{
C.F Mat Taib ${ }^{{ }^{* 1}}$, S.S Iqubal ${ }^{2}$,Fauziah Md Yusof ${ }^{3}$,S.Kasolang ${ }^{4}$ \\ ${ }^{1,2,34}$ Faculty of Mechanical Engineering, Universiti Teknologi Mara \\ *Corresponding author E-mail: che_faridah04@yahoo.com
}

\begin{abstract}
Wudhu (ablution) ritual is an activity of cleaning physical parts for Muslims to perform their prayer five times per day. During this wudhu ritual process, the water is allowed to run free and drain away. At-times, this has caused some concerns particualrly on water wastage. Many organizations in Malaysia such as AACE Technologies Sdn. Bhd. came out with a solution and steps as "Auto Wudu Washer" in order to overcome this wastage, but the result was not satisfying enough. This study introduces a wudhu system that can reduce the amount of water usage during wudhu ritual consistently by limiting around 1 litre per consumer. Generally, there were seven (7) parts that have been used in this project such as 1 litre of container, magnet, float, valve push button, washer and cap. These designs did not utilize any electronic devices. Using these parts, 2 experiments were conducted namely the current wudhu system and the upgraded wudhu system by 10 (Muslims) respectively. The result of this project confirmed that using the Upgraded Wudhu System with amount of water limited to 1 litre per consumer was better than the current wudhu system by ten times.
\end{abstract}

Keywords: ablution, wastage, wudhu system, electronic devices

\section{Introduction}

Water is one of the prime elements responsible for life on earth. Every human being relies on water for life and good health, but for Muslims, water has a special and sacred purpose used for wudhu or ablution, a must before one proceeds to perform a prayer. As is emphasized in the Qur'an; "O you who believe! When you stand up for ritual prayer (salah), wash your face and your hands up to the elbows, and wipe a part of your head and your feet up to ankles." (5:6)[1]

Wudhu ritual has been practiced among Muslims for centuries. But as a human being, people tend to be careless and waste a lot of water while performing wudhu. Wastefulness is a very despicable behaviour that is forbidden in Islam. Even the Prophet Muhammad (s.a.w) urged moderation when using water during the wudhu ritual. He, himself used a minimal amount of water, using just one Mudd of water (equivalent to $625 \mathrm{ml}$ ) when carrying out wudhu [2].

The Prophet once saw Sa'd performing wudhu ritual and said to him: "Why are you wasting a lot of water?" Sa'd asked, "Is there wastefulness even in performing wudhu?" The Prophet replied, "Yes, even if you were at a flowing river" [2]. This scenario proves that such attitude is not approved in Islam.

Nowadays, it is difficult to control the amount of water used by a consumer to complete a wudhu ritual. A typical wudhu ritual process required of about 6 to 9 liters of water in volume. An effort of designing a wudhu system that could provide a better awareness to the consumer regarding the wastefulness attitude is not yet available. The 'Auto Wudu Washer'(AAW) was introduced in 2010[3].In this system the water flow is controlled using sensor activated taps that could save water 1.0 to 1.5 litres for one ablution. The 'SmartWudhu' system project was conducted by students from Universiti Tun Hussein Onn Malaysia in 2014 [4].This project applied the concept of recycling ablution water using water treatment method.

\section{Methodology}

The aim of this project was to design and to fabricate a wudhu system that could reduce the amount of water used by Muslims when taking wudhu at the UiTM Shah Alam mosque by fabricating a prototype for this system. Figure 1 shows the design and fabrication flowchart for making the prototype of prototype of the Upgraded Wudhu System.

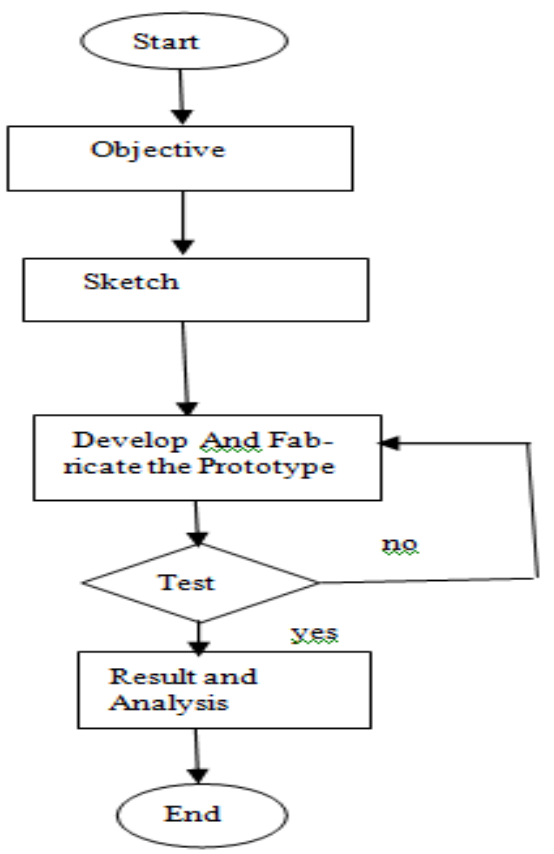

Figure 1: The Flow Chart For Making The Prototype

Copyright $\odot 2018$ Authors. This is an open access article distributed under the Creative Commons Attribution License, which permits unrestricted use, distribution, and reproduction in any medium, provided the original work is properly cited. 
A specific computer software, CATIA was deployed to shape, and visualize the models in $3 \mathrm{D}$. The $2 \mathrm{D}$ drawing of the parts is shown in Figure 2.

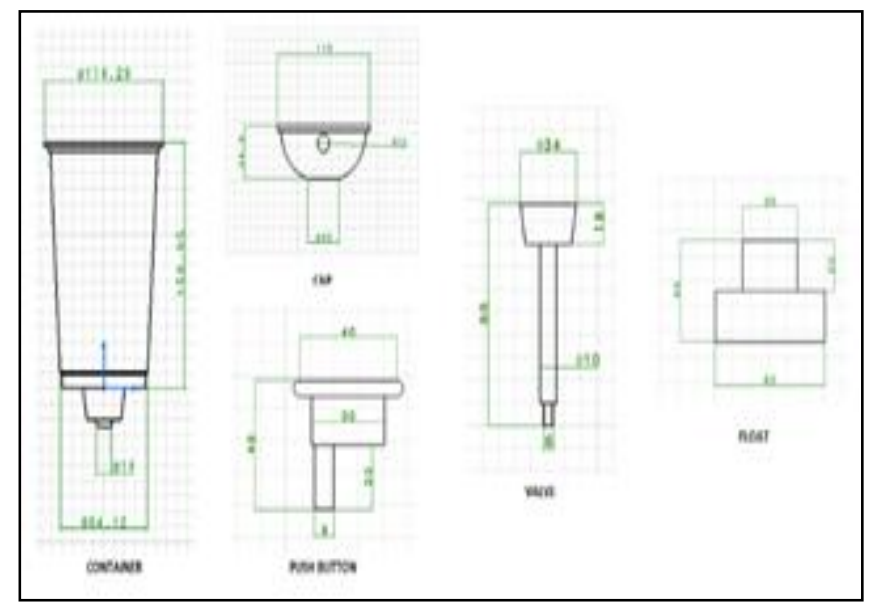

Figure 2: Upgraded Wudhu System in CATIA with parts and dimensions

There were seven (7) parts in the Upgraded Wudhu System. as shown in Figure 3. Detailed drawing produced by CATIA were later used to fabricate the components of the prototype using $3 \mathrm{D}$ printing technology.
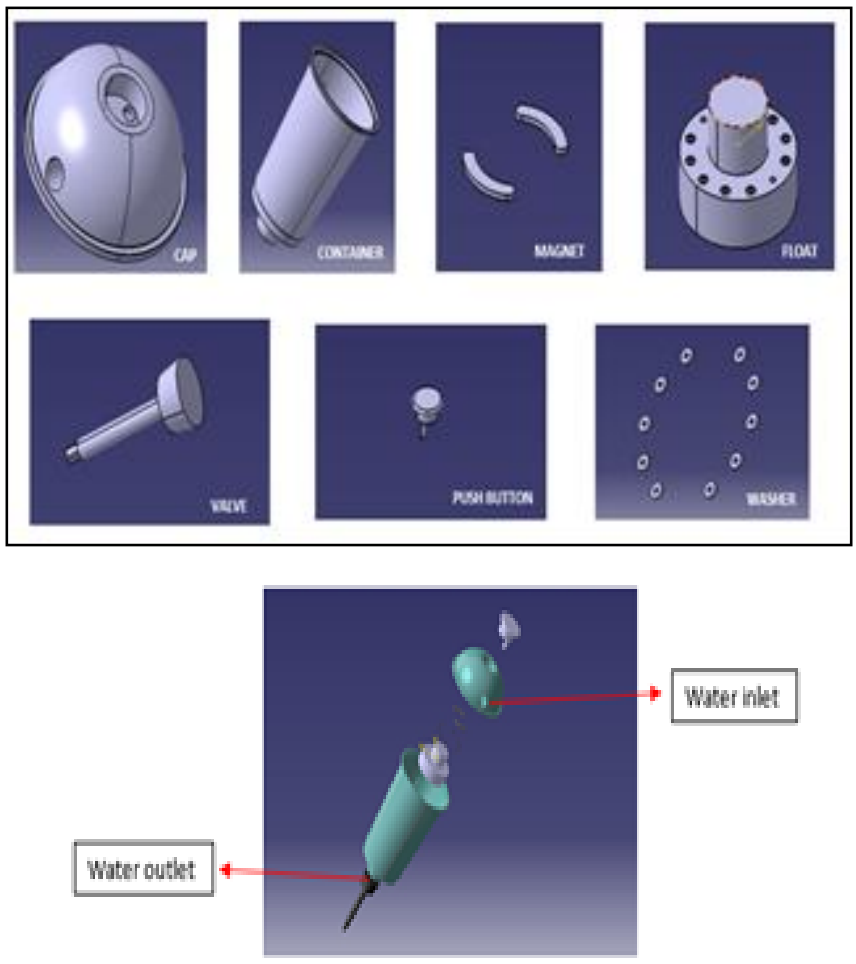

Figure 3: Parts of Upgraded Wudhu System

The material of the structure components used for making the prototype are given in Table 1.

Table 1: Material of components

\begin{tabular}{|l|l|l|}
\hline No & Component & Material \\
\hline 1 & Cap & Light fibre glass \\
\hline 2 & Valve & Iron and plastic \\
\hline 3 & Container & plastic \\
\hline 4 & Push button and spring & $\begin{array}{l}\text { Aluminium and } \\
\text { iron }\end{array}$ \\
\hline 5 & Washer & Rubber \\
\hline 6 & magnet & Iron \\
\hline 7 & float & polystyrene \\
\hline
\end{tabular}

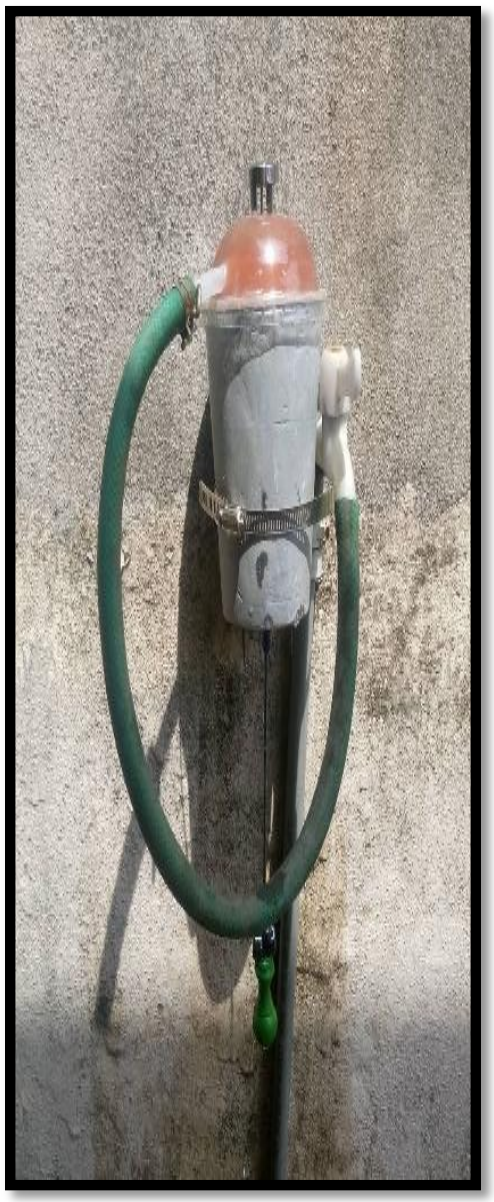

Figure 4: The Complete Set of Upgraded Wudhu System

Figure 4 shows the complete set of Upgrade Wudhu System before being used at the main source of water. The Upgraded Wudhu System process flow started once the consumer pressed the push button located at the top of the container. When the push button was pressed, the float that stopped the water from over flowing would hold the water down inside the container. When the water filledthe container, the float with washer would then rise with the water level until it was attracted by a magnet at the bottom part of the cap. This would cause the water to stop flowing until the push button was pressed again. The valve function as a stopper to keep the water from flowing out. During the ablution process, the consumer need to push the valve upward to let the water flow out. During wudhu, the consumer needed to push the valve was let go, the water would stop flowing out. The valve required a soft touch to be functioning which made it practical to be use.

\section{Experimental Procedure}

The data was collected from 10 consumers for each system. The amount of water consumed by each consumer was calculated based on the time usage for each wudhu ritual. The assumptions of the experiments are incompressible flow, steady flow, and with fully laminar developed flow. Water density is $1000 \mathrm{~kg} / \mathrm{m}^{3}$.

Experiment I : Water Consume by Each Consumer Using the Current Wudhu System

The recorded data on the amount water consumed by 30 consumers at UiTM mosque for 5 different times of prayer using the current wudhu system is shown in Table 2 The current wudhu system is a system that do not utilize any advanced mechanism. The system was designed using simple piping construction which was widely used in most of the mosques around the world can be seen in Figure 5 

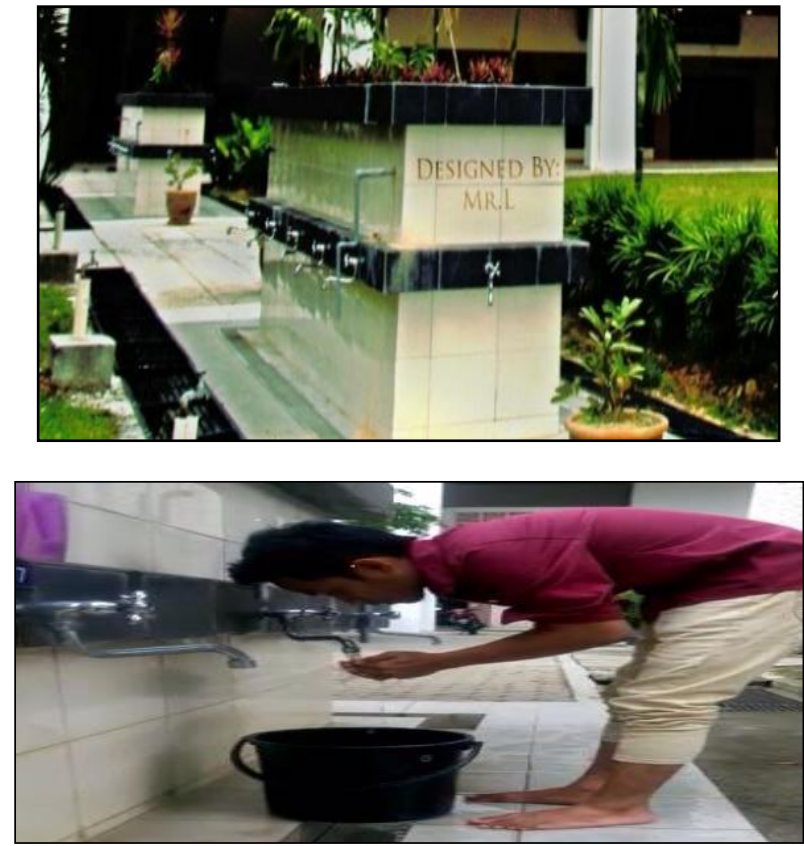

Figure 5: A Consumer Taking Wudhu Using The Current Wudhu System During Experiment 1

Table 2: Water Consume by Each Consumer Using The Current Wudu System

\begin{tabular}{|c|c|c|c|c|c|c|}
\hline \multirow{2}{*}{$\begin{array}{c}\text { No. of } \\
\text { consumer }\end{array}$} & \multicolumn{5}{|c|}{ Water Consume in Litre (L) } & \multirow{2}{*}{$\begin{array}{c}\text { Total } \\
\text { (L) }\end{array}$} \\
\hline & Fajr & Dhuhr & Asr & Maghrib & Isha'a & \\
\hline 1 & 7.14 & 7.80 & 7.67 & 7.21 & 7.42 & 37.24 \\
\hline 2 & 8.80 & 8.83 & 8.83 & 8.78 & 8.81 & 44.05 \\
\hline 3 & 8.70 & 8.83 & 8.96 & 8.76 & 8.88 & 44.13 \\
\hline 4 & 7.03 & 7.54 & 7.61 & 7.42 & 7.45 & 37.05 \\
\hline 5 & 8.31 & 8.74 & 8.77 & 8.68 & 8.71 & 43.21 \\
\hline 6 & 7.54 & 7.68 & 7.69 & 7.56 & 7.55 & 38.02 \\
\hline 7 & 9.81 & 9.28 & 9.29 & 9.27 & 9.27 & 46.92 \\
\hline 8 & 6.93 & 7.07 & 7.05 & 7.13 & 7.01 & 35.19 \\
\hline 9 & 9.28 & 9.34 & 9.23 & 9.33 & 9.31 & 46.49 \\
\hline 10 & 8.11 & 8.24 & 8.31 & 8.26 & 8.18 & 41.10 \\
\hline total & & & & & & 413.4 \\
\hline
\end{tabular}

\subsection{Sample Calculation 1:}

Water consume by 10 consumers or wudhu ritual during Fajr to Isha' $=413.4 \mathrm{~L}$

Average volume per person for 5 times $=413.4 / 10$

$=41.34 \mathrm{~L}$

Average volume per person for each prayer $=41.34 / 5$

$=8.26 \mathrm{~L}$

In experiments 1 , it can be observed that there were variations of the amount of the water used for taking wudhu using the current wudhu sysytem. The 10 consumers for experiment 1 having different age ranging from 15 to 50 year old, generally use approximately 35 to 46 liters of water perday for 5 prayers from Fajr to Isha.

Based on the water consumption in Table 2, the average volume of water in litre (L) consumed by each consumer for 5 different times of prayer a day was calculated. A typical wudhu process using the current wudhu system required about 8.26 litres of water per consumer for every wudhu. The total amount of water consumed by 10 Muslims a day is 413.4 litres.It was noted that the participants tend to use more water during Dhuhur and Asr prayers compared to other prayer times Especially during Dhuhr and Asr prayer time. This might be influenced by the weather condition. Therefore, the average volume of water used for one full ablution is 8.26 litres. This result is similar to the result discovered by Nor Haliza et al in 2013 [6] which was about 6 to 9 liters
Experiment II : Water Consume by Each Consumer Using Upgraded Wudhu System

Experiment II was conducted by implementing the same procedures as in Experiment I but the current system was replaced with the prototype of the Upgraded Wudhu System. Table 3 shows that the consumers used about 3.8 to 4.8 liters perday from Fajr to Isha prayer. The system was designed by altering the toilet flush system, where the concept of pushing the button for every refill was adapted into the Upgraded Wudhu System. Besides that, the Upgraded Wudhu System also could be considered as mechanical wudhu system since it fully utilised mechanical components and parts without any electronic assistance. Figure 6 shows the wudhu performed using the Upgraded Wudhu System.

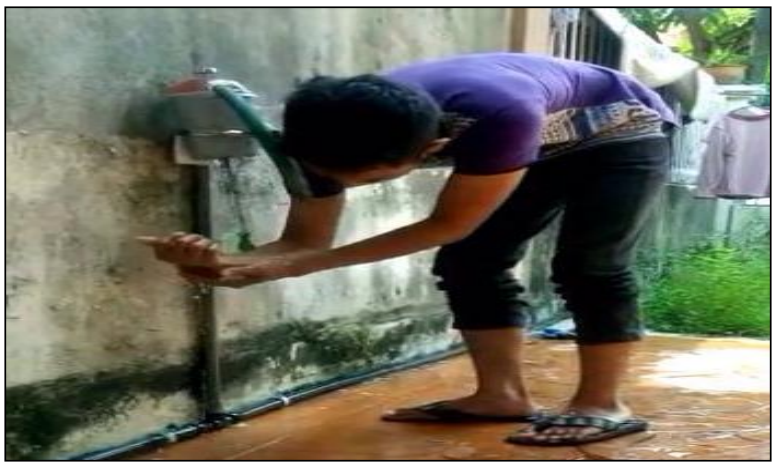

Figure 6: A Consumer Taking Wudhu Using The Upgraded Wudhu System During Experiment 2

Table 3: Water Consume by Each Consumer Using The Current Wudhu System

\begin{tabular}{|c|c|c|c|c|c|c|}
\hline \multirow{2}{*}{$\begin{array}{c}\text { No. of } \\
\text { consumer }\end{array}$} & \multicolumn{5}{|c|}{ Water Consume in Litre (L) } & \multirow{2}{*}{$\begin{array}{c}\text { Total } \\
(\mathrm{L})\end{array}$} \\
\cline { 2 - 6 } & Fajr & Dhuhr & Asr & Maghrib & Isha'a & (2) \\
\hline 1 & 0.72 & 0.87 & 0.77 & 0.75 & 0.73 & 3.84 \\
\hline 2 & 0.87 & 0.97 & 0.98 & 0.93 & 1.00 & 4.75 \\
\hline 3 & 0.78 & 0.88 & 0.85 & 0.81 & 0.90 & 4.22 \\
\hline 4 & 0.77 & 0.80 & 0.88 & 0.85 & 0.85 & 4.15 \\
\hline 5 & 0.92 & 1.00 & 0.97 & 0.95 & 0.95 & 4.79 \\
\hline 6 & 0.92 & 0.97 & 0.95 & 0.87 & 0.85 & 4.56 \\
\hline 7 & 0.83 & 0.90 & 1.00 & 0.85 & 0.77 & 4.35 \\
\hline 8 & 0.88 & 0.98 & 0.90 & 0.83 & 0.90 & 4.49 \\
\hline 9 & 0.91 & 1.00 & 1.15 & 0.95 & 0.96 & 4.97 \\
\hline 10 & 0.95 & 1.00 & 0.98 & 1.00 & 0.95 & 4.88 \\
\hline total & & & & & & 45 \\
\hline
\end{tabular}

\subsection{Sample of Calculation 2:}

Water consume by 10 consumers or Wudhu ritual during Fajr to Isha' $=45 \mathrm{~L}$

Average volume per person for 5 times prayer $=45 / 10$

$=4.5 \mathrm{~L}$

Average volume per person for each pray $=4.5 / 5$

$=0.9 \mathrm{~L}$

Based on the data collected, the average volume of water in litre (L) consumed by each consumer for 5 different time prayers a day was calculated. The average amount of water required to perform wudhu ritual by every Muslims a day would be around $1 \mathrm{~L}$ using Upgraded Wudhu System. In total water consumed by a person for 5 times prayer would be around 5 litres and for 10 Muslims a day it would be 45litres.

\section{Results and Discusssion}

From the calculation of the comparison of the current wudhu system and the Upgraded Wudhu System, it is proven that the Upgraded Wudhu System could reduce the amount of water used for 
wudhu ritual. current wudhu system consumed ten (10) times more water as compared to Upgraded Wudhu System. Based on this result, the differences calculated were around 368.4 litre per day. This shows that, deployment of a proper wudhu system could successfully overcome the issue of Muslims consuming excessive water while performing the wudhu ritual.

\section{Conclusion}

Based on the observation it was clear that an effective way to reduce water used for wudhu ritual while the same time promoting the positive habit of among Muslims in conserving water was by implementing the optimised wudhu system. This Upgraded Wudhu System was materialized by considering the economical aspect so that the mosque administrative could solve the issue by replacing the current system with the Upgraded Wudhu System. Since the Upgraded Wudhu System did not require any reconstruction, it would be more practical to use this system as a replacement of the current system. Moreover, the Upgraded Wudhu System required a minimal cost to implement for being completely mechanical with no electrical configuration and yet very effective.

\section{References}

[1] Kamal A.M,(2008),Fikih Thaharah, Jakarta Timur

[2] Faruqui, N.I,(2003),Water,Human Rights, and Economics Instruments the Islamic Perpective, Journal of Water Resources Development,vol 9/10

[3] AACE Technologies Sdn Bhd. (2010). Islamic Pre-prayer Ablution System. Auto Wudu Washer. Petaling Jaya, Malaysia.

[4] Azeanita Suratkon, C. M. (2014). SmartWUDHU'-Recycling Ablution Water for Sustainable Living in Malaysia. Journal of Sustainable Development; Vol. 7, No. 6, 150-157.

[5] Nor Haliza Johari, O. H. (2013). A Behaviour Study on Ablution Ritual among Muslim in Malaysia. Social and Behavioral Sciences, 6-9 